\title{
Polinização seletiva em maracujazeiro amarelo (Passiflora edulis f. flavicarpa) monitorada por vetores canônicos
}

\author{
Seletive pollination in yellow passion fruit (Passiflora edulis f. flavicarpa) by canonic vectors
}

\author{
Alexandre Pio Viana ${ }^{\mathrm{I}}$ Edenio Detmannn ${ }^{\mathrm{II}}$ Messias Gonzaga Pereira ${ }^{\mathrm{I}}$ Margarete Magalhães de Souza ${ }^{\mathrm{III}}$ \\ Telma Nair Santana Pereira ${ }^{I}$ Antônio Teixeira do Amaral Júnior ${ }^{I}$ Gustavo Menezes Gonçalves ${ }^{I}$
}

\section{RESUMO}

Objetivou-se neste trabalho avaliar a influência da planta doadora de pólen sobre as características dos frutos produzidos na cultura do maracujazeiro-amarelo (Passiflora edulis $f$. falvicarpa). Neste contexto, um experimento foi conduzido, segundo o esquema de cruzamentos controlados. Empregaram-se 23 plantas "genitor masculino" e 103 plantas receptoras de pólen, perfazendo o total de 185 frutos avaliados segundo as características: peso, largura, comprimento, número de sementes e peso relativo de 100 sementes. A avaliação dessas características, segundo análise de variância multivariada (MANOVA), permitiu a verificação de efeitos significativos ("genitor masculino" $e$ "fêmea hierarquizada a genitor masculino"). A partir das informações da MANOVA, construiu-se uma função discriminante, constituída pela primeira variável canônica baseada na matriz de soma de quadrados para a fonte de variação "genitor masculino" (Importância relativa $=58,10 \%)$. A análise desta permitiu verificar elevado efeito da fonte de variação "genitor masculino" sobre as características dos frutos, cujos indivíduos foram agrupados univariamente em três grupos distintos. Tais resultados permitem concluir que tanto progenitores femininos como masculinos podem influenciar os resultados obtidos em esquemas de seleção massal.

Palavras-chave: cruzamentos, maracujá amarelo, seleção massal, polinização seletiva.

\section{ABSTRACT}

This research was aiemd at evaluating the influence of the relactive pollination of pollen donor plant in obtaition higher fruits of yellow passion (Passiflora edulis $f$. falvicarpa).
To do so, an experiment was conduced according to the controlled crosses, using 23 male plants and 103 pollen receptor plants. The total of fruits obtained was 185 units, that were evaluated according to the following traits: fruit weight, fruit diameter, fruit length, fruit seed number and relative weight of 100 seeds. The data were analyzed by using multivariate analysis (MANOVA). The discriminant function was constituted by the first canonic variable based on matrix of square sum of male (relative importance $=58.1$ ). The discriminant function analysis permitted to verify high effect of male in relation to fruit traits, whose individuals were grouped in three distinct classes. The results indicate that female as well as male can influence the results obtained in mass selection.

Key words: crosses, passion fruit, mass selection, selective pollination.

\section{INTRODUÇÃO}

O maracujazeiro amarelo (Passiflora edulis

f. flavicarpa) é uma espécie frutífera que, apesar da grande importância, tem sido pouco investigada em estudos de melhoramento genético aplicado. Para o estabelecimento desses estudos, torna-se de fundamental importância investigar a estrutura genética de populações cultivadas a fim de se identificarem genitores promissores para a geração de híbridos suficientemente heteróticos e conseqüente obtenção de segregantes superiores e, com base em

\footnotetext{
'Laboratório de Melhoramento Genético Vegetal, Centro de Ciências e Tecnologias Agropecuárias, Universidade Estadual do Norte Fluminense Darcy Ribeiro. Av. Alberto Lamego 2000, 28015-620, Campos dos Goytacazez, RJ, Brasil. E-mail: pirapora@uenf.br. Autor para correspondência.

ID Departamento de Zootecnia, Universidade Federal de Viçosa (UFV), 36571-000, Viçosa, MG, Brasil.

IIIDepartamento de Ciências Biológicas, Universidade Estadual de Santa Cruz, Km 16, 45650-000, Rod. Ilhéus, Itabuna, BA.
} 
tal informação, estabelecerem-se programas de melhoramento genético para essa cultura.

A importância da diversidade genética para o melhoramento reside no fato de cruzamentos envolvendo genitores geneticamente distantes serem os mais convenientes para se produzirem elevado efeito heterótico e maior variabilidade genética em gerações segregantes (RAO et al., 1981; CRUZ, 1990). Apesar da importância, poucos têm sido os estudos de avaliação de grupos heteróticos de maracujazeiro amarelo, visando à indicação de cruzamentos para futuros programas de melhoramento com a cultura. Os estudos até então desenvolvidos têm dado atenção em trabalhos com parâmetros genéticos (VIANA et al., 2004, MORAES et al., 2005), estudos de correlações entre caracteres (VIANA et al., 2003a), estudos com as espécies relacionadas e suas características reprodutivas (MELETTI et al., 2003, VIANA et al., 2003b, SOUZA et al., 2003, 2004a, 2004b), além de estudos sobre diversidade genética em populações (VIANA et. al., 2006).

Nas várias regiões do Brasil que cultivam essa fruta, a seleção massal é o método utilizado para selecionar frutos que serão empregados na extração de sementes e produção de mudas para os próximos plantios. Entretanto, esta prática não tem sido eficiente, pois, na seleção massal, a escolha dos melhores indivíduos baseia-se no fenótipo da planta mãe ou genitor feminino. Tal estratégia não tem permitido a obtenção de resultados consistentes em relação à ampliação da freqüência de alelos favoráveis para as características de interesse. Um dos possíveis problemas relacionados a esta inconsistência de resultados pode residir na utilização indiscriminada de plantas doadoras de pólen, para a obtenção de sementes para o próximo plantio. Assim, esta contribuição genética à formação da próxima geração de cultivo tem sido desconsiderada nos processos de seleção.

O objetivo deste trabalho foi verificar a influência da planta doadora de pólen sobre as características dos frutos de genitores femininos em esquema de cruzamento hierárquico para a cultura do maracujazeiro-amarelo.

\section{MATERIAL E MÉTODOS}

Foram retiradas amostras ao acaso de plantas na área da Empresa Bela Joana, em Campos dos Goytacazes-RJ, no período de maio a julho de 2002, oriundas de várias populações, conforme procedimentos recomendados pelo Programa Frutificar, compostas das seguintes populações: materiais de São
Francisco do Itabapoana, Maguary e Yellow Máster. Todos os indivíduos que foram utilizados no trabalho foram amostrados aleatoriamente na população, não sendo possível a identificação dos mesmos individualmente, por população de origem. Os cruzamentos foram realizados utilizando-se uma planta doadora de pólen com um grupo de plantas receptoras, obtendo-se três frutos por genitora feminina. Empregou-se relação de cruzamento variando de 1:3 a 1:5, perfazendo um total de 23 plantas doadoras de pólen e 103 receptoras. Na ocasião em que todos os indivíduos apresentavam pleno florescimento, as flores dos genitores femininos foram marcadas e ensacadas com sacos de papel. Após 12 horas e 30 minutos, a proteção foi retirada e o pólen dos genitores masculinos transferidos para o estigma das genitora feminina esfregando-se as anteras na superfície dos estigmas, alocando-se nos cruzamentos a máxima quantidade de pólen, evitando-se assim que diferenças no número de grãos de pólen no ato da polinização pudessem interferir nos resultados das avaliações dos frutos. Logo em seguida, as flores foram novamente ensacadas para se evitar a contaminação por pólen estranho. Vinte e quatro horas após esse procedimento, os sacos de papel foram retirados e as flores marcadas com etiquetas, com a data do cruzamento e o respectivo genitor masculino doador do pólen. Quinze dias após, os frutos foram ensacados com sacos de náilon para proteção, evitando que os frutos ao amadurecer fossem perdidos ao chão.

Os frutos foram coletados e trazidos ao Laboratório de Melhoramento Genético Vegetal, no Setor de Melhoramento de Plantas, na Universidade Estadual do Norte Fluminense Darcy Ribeiro (UENF), para a avaliação dos genitores femininos. Em tal fase, foram feitas as seguintes avaliações: a) Peso de fruto: obtido pela pesagem dos frutos maduros em balança eletrônica OHADUS, modelo TP 4000D, com capacidade para 4,0kg e precisão de 0,01 grama; b) Comprimento dos frutos: obtido a partir da medida do comprimento longitudinal, com a utilização de paquímetro; c) Largura dos frutos: obtida pela quantificação do comprimento transversal, com a utilização de paquímetro; d) Número de sementes: obtida após secagem em estufa de circulação forçada com temperatura ambiente, e então realizada a contagem das sementes, e) Peso de cem sementes: obtido através de pesagem em balança analítica com capacidade de até $250 \mathrm{~g}$.

As análises estatísticas foram implementadas conforme o modelo:

$Y_{i j k}=\mu+M_{i}+F(M)_{i j}+\varepsilon_{(i j) k}$, em que: $\mathrm{Y}_{\mathrm{ijk}}=$ resposta experimental relativa ao fruto $\mathrm{k}$ produzido pelo cruzamento entre o "genitor masculino" i e a "genitora 
feminina” $\mathrm{j} ; \mu$ = média geral; $\mathrm{M}_{\mathrm{i}}=$ efeito relativo ao "genitor masculino" i;

$\mathrm{F}(\mathrm{M})_{\mathrm{ij}}=$ efeito relativo à "genitora feminina"

j hierarquizada ao "genitor masculino" i; e $\varepsilon_{(\mathrm{ij)})}=$ erro experimental, associado a cada observação, pressuposto NID $\left(0, \sigma^{2}\right)$.

Inicialmente, as características dos frutos foram submetidas à análise de variância uni e multivariada, empregando-se somas de quadrado tipo III (STEEL et al., 1997).

A partir das informações geradas pela análise multivariada, na qual se obtêm os vetores canônicos e testes estatísticos considerando-se as várias características estudadas simultaneamente, produziram-se variáveis canônicas discriminantes para o efeito de "genitor masculino", sendo a equação característica produzida a partir da restrição (HARRIS, 1975): $\operatorname{det}\left[E^{-1} H-\lambda I\right]=0$, em que: $E=$ matriz de somas de quadrados para o efeito de "genitora feminina" hierarquizada ao efeito de "genitor masculino"; $\mathrm{H}$ = matriz de somas de quadrados para o efeito de "genitor masculino"; $\lambda=$ autovalor canônico; e I = matriz identidade de ordem $n=5$.

A partir do maior autovalor obtido por intermédio da equação característica, produziu-se o autovetor correspondente (SEARLE, 1966), o qual foi submetido à normalização por intermédio da restrição: $v^{\prime} E v=1$, em que: $v=$ autovetor e $E=$ ao definido anteriormente.

A partir do autovetor canônico associado ao maior autovalor da equação característica definida em HARRIS (1975), produziu-se uma nova variável formada pela combinação linear de todas as características avaliadas nos frutos (com a utilização dos coeficientes canônicos estimados pela análise, multiplicaram-se os coeficientes canônicos pela média da característica, formando uma combinação linear entre as variáveis), a qual passou a ser denominada primeira variável discriminante canônica (PVDC). Esta foi ressubmetida à análise de variância univariada, sendo, posteriormente, as médias relativas às diferentes plantas doadoras de pólen submetidas à análise de agrupamento univariado, segundo os protocolos descritos por SCOTT \& KNOTT (1974). Para todos os procedimentos estatísticos fixou-se em 5\% o nível crítico de probabilidade de ocorrência do erro tipo I.

\section{RESULTADOS E DISCUSSÃO}

Verificou-se elevado nível de significância para o efeito "genitor masculino" para as características avaliadas, exceto para a variável peso de 100 sementes (Tabela 1). De outra forma, tal tendência não foi verificada integralmente ao segundo efeito avaliado, genitora feminina hierarquizada a genitor masculino.

No entanto, a despeito da ausência de significância associada a esse efeito na característica número de sementes, a avaliação destas de forma conjunta, por intermédio de análise de variância multivariada (MANOVA), manteve a tendência geral de influência de ambas as fontes de variação sobre os frutos, evidenciando claramente que ambos os genitores tem efeitos sobre as características dos frutos produzidos (Tabela 1 ).

Com base nas informações geradas por intermédio da MANOVA, procedeu-se à construção das variáveis canônicas baseadas sobre a matriz de soma de quadrados para a fonte de variação "genitor masculino”. Segundo informações expressas na tabela 2, o autovalor empregado na construção do primeiro autovetor canônico, aqui denominado "primeira variável discriminante canônica” (PVDC), apresentou importância relativa de 58,10\%. Tal informação implica o fato de que proporção similar associada ao poder total de discriminação entre grupos foi conservada na redução do espaço euclidiano de comparação de cinco para uma única dimensão. Ou seja, quando se avaliava o grupo de cruzamentos com base nas cinco características avaliadas e com a construção de PVDC, passou-se a ter somente uma variável, que é formada pela combinação linear das demais. Com base nesta premissa, argumenta-se que o ganho operacional analítico obtido com tal redução permitirá suplantar a ausência de conservação do restante dos aspectos discriminatórios sobre a nova variável gerada, garantindo assim que haverá integridade de comparações entre os cruzamentos e será possível avaliar com eficiência o efeito do genitor masculino sobre as características dos frutos.

O emprego da primeira variável canônica como elemento de discriminação permite que se construa uma nova variável, como combinação linear daquelas originalmente mensuradas, de forma a demonstrar-se a máxima discriminação entre os grupos associados à fonte de variação utilizada como base para sua construção; neste caso, efeito de genitor masculino (HARRIS, 1975). Dessa forma, a utilização da PVDC tem como objetivo visualizar possíveis discriminações entre plantas doadoras de pólen ("genitores masculinos"), de forma a verificar-se a existência de influências efetivas dessa fonte sobre as características dos frutos produzidos. Assim, ressaltase que a PVDC não infere diferenças entre grupos, mas somente equaliza a combinação linear entre variáveis de forma a se obter o máximo valor da estatística F para a fonte de variação avaliada. 
Tabela 1 - Níveis descritivos de probabilidade para o erro tipo I associados às hipóteses de nulidade para ausência de efeitos relativos a “Genitor masculino” e "Genitora feminina hierarquizada a genitor masculino” para diferentes características dos frutos.

\begin{tabular}{|c|c|c|}
\hline \multirow{2}{*}{ Característica do fruto } & \multicolumn{2}{|r|}{ Efeito } \\
\hline & “Genitor masculino” & “Genitora feminina hierarquizada a genitor masculino” \\
\hline Comprimento (mm) ${ }^{1}$ & 0,0204 & 0,0005 \\
\hline Largura $(\mathrm{mm})^{1}$ & 0,0001 & $<0,0001$ \\
\hline Peso $(g)^{1}$ & 0,0002 & 0,0028 \\
\hline Peso de 100 Sementes $(\mathrm{g})^{1}$ & 0,4388 & 0,9504 \\
\hline Número de Sementes (un) ${ }^{1}$ & 0,0002 & 0,6151 \\
\hline Avaliação Conjunta² & 0,0002 & 0,0002 \\
\hline PVDC $^{1,3}$ & $<0,0001$ & 0,1892 \\
\hline
\end{tabular}

1/ Avaliações realizadas por intermédio do teste F. ${ }^{2 /}$ Avaliações realizadas por intermédio do teste $\lambda$ de Wilks. ${ }^{3 /}$ PVDC = primeira variável discriminante canônica.

Esses argumentos podem ser mais bem verificados sobre os resultados da análise de variância univariada para a PVDC (Tabela 1), em que se observou alta significância para a fonte de variação "genitor masculino”. Esclarece-se, em adição, que a não verificação de significância associada ao efeito "genitora feminina hierarquizada a genitor masculino" constitui reflexo da utilização da matriz associada à fonte de variação "genitor masculino", a qual permite tão somente a maximização da visualização dos efeitos associados a esta fonte, em detrimento às demais presentes no modelo.

Baseando-se nos resultados obtidos com a análise de variância univariada para a PVDC (Tabela 1), procedeu-se à comparação entre genitores masculinos como base no rendimento médio das características avaliadas, isto é, foram obtidas as médias das genitoras femininas que receberam pólen de determinado genitor masculino (Tabela 3), segundo os protocolos da análise de agrupamento univariada de SCOTT \& KNOTT (1974), cujos resultados são expressos na figura 1.

Segundo os protocolos de SCOTT \& KNOTT (1974), pôde-se verificar a discriminação das plantas doadoras de pólen em três grupos distintos (Figura 1): um primeiro (G1), formado apenas pelo indivíduo 19; um segundo (G2), constituído pelos indivíduos 2, 3, 4, 5, 6, 7, 8, 9, 15, 18; e um terceiro (G3), formado pelos indivíduos 1, 10, 11, 12, 13, 14, 16, 17.

A investigação descritiva destes grupos com base nas variáveis originalmente mensuradas (Tabela 3) indicou que os frutos produzidos nos cruzamentos com G1 são extremamente superiores aos demais, com as genitoras femininas que receberam pólen desse genitor masculino tendo um peso médio de fruto de 300,3 gramas, comprimento médio de 114,4 cm e largura média de 89,7cm. Em adição, aqueles produzidos a partir de cruzamentos com indivíduos constituintes de G2 assumiram, neste rol, posicionamentos intermediários, com peso médio no grupo de 161,2 gramas, comprimento e largura com média de 73,89 cm e 83,00cm, respectivamente. Já o G3 foi responsável pela produção dos frutos relativamente inferiores em relação ao conjunto avaliado, com peso médio no grupo de 121,2g, comprimento e larguras médios de $68,78 \mathrm{~cm}$ e $75,66 \mathrm{~cm}$, respectivamente.Tal comportamento parece inferir claramente aos sistemas

Tabela 2 - Autovalores, autovetores canônicos (coeficientes canônicos) e respectivas importâncias relativas extraídos com base na matriz H de soma de quadrados para o efeito de "Genitor masculino".

\begin{tabular}{|c|c|c|c|c|c|}
\hline & \multicolumn{5}{|c|}{ Variável canônica } \\
\hline & $1^{\underline{a}}$ & $2^{\underline{a}}$ & $3^{\underline{a}}$ & $4^{\underline{\underline{a}}}$ & $5^{\underline{a}}$ \\
\hline Autovalores canônicos & 1,2806 & 0,3537 & 0,2341 & 0,1975 & 0,1384 \\
\hline Largura de fruto (mm) & $-0,00995$ & 0,00853 & $-0,00719$ & 0,01599 & $-0,01739$ \\
\hline Comprimento de fruto (mm) & 0,00701 & $-0,00679$ & 0,01413 & 0,00213 & $-0,00510$ \\
\hline Peso de fruto (g) & 0,00152 & $-0,00095$ & $-0,00242$ & $-0,00156$ & 0,00375 \\
\hline Peso de 100 sementes (g) & 0,05156 & 1,60951 & 0,70013 & 1,10706 & 1,01501 \\
\hline Número de sementes (un) & 0,00076 & 0,00070 & 0,00012 & $-0,00042$ & $-0,00037$ \\
\hline Importância relativa (\%) & 58,10 & 16,05 & 10,62 & 8,96 & 6,28 \\
\hline
\end{tabular}


Tabela 3 - Médias de quadrados mínimos para as diferentes características de frutos estudadas e para a primeira variável discriminante canônica de acordo com o "Genitor masculino" avaliado.

\begin{tabular}{lcccccc}
\hline & \multicolumn{5}{c}{ Variável $^{1}$} \\
\cline { 2 - 6 } “Genitor masculino" & LARG & COMP & PESO & PESO100 & NUMS & PVDC \\
\cline { 2 - 6 } & 69,1 & 75,8 & 116,7 & 2,142 & 290,4 & 0,3520 \\
1 & 73,4 & 85,1 & 163,4 & 2,143 & 389,2 & 0,5210 \\
3 & 77,4 & 88,9 & 184,6 & 2,143 & 330,2 & 0,4950 \\
4 & 72,6 & 82,6 & 153,7 & 2,115 & 295,5 & 0,4242 \\
5 & 72,2 & 79,7 & 153,7 & 2,091 & 330,7 & 0,4329 \\
6 & 78,6 & 88,3 & 186,5 & 2,124 & 348,2 & 0,4951 \\
7 & 75,2 & 80,8 & 159,5 & 2,140 & 321,9 & 0,4157 \\
8 & 73,5 & 83,1 & 165,7 & 2,138 & 334,1 & 0,4673 \\
9 & 72,3 & 76,8 & 149,1 & 2,161 & 371,8 & 0,4389 \\
10 & 68,2 & 74,6 & 133,0 & 2,414 & 290,2 & 0,3777 \\
11 & 66,9 & 74,9 & 124,1 & 2,143 & 282,7 & 0,3728 \\
12 & 72,4 & 77,2 & 130,1 & 2,142 & 258,2 & 0,3258 \\
13 & 70,7 & 79,4 & 125,9 & 2,141 & 246,5 & 0,3418 \\
14 & 68,2 & 73,6 & 106,2 & 2,173 & 266,5 & 0,3134 \\
15 & 74,9 & 80,3 & 162,2 & 2,141 & 402,6 & 0,4801 \\
16 & 66,6 & 73,7 & 107,9 & 2,148 & 276,6 & 0,3390 \\
17 & 76,1 & 124,6 & 2,145 & 173,3 & 0,2867 \\
18 & 68,2 & 84,0 & 134,4 & 2,140 & 390,2 & 0,5150 \\
19 & 68,8 & 114,4 & 300,3 & 2,179 & 501,3 & 0,8588 \\
\hline
\end{tabular}

1/ COMP = comprimento do fruto (mm); LARG = largura do fruto (mm); PESO = peso do fruto (g); PESO100 = peso de cem sementes (g); NUMS = número de sementes (un); PVDC = primeira variável discriminante canônica.

de cruzamento similares ao aqui empregado o efeito da planta doadora de pólen, ao menos em termos introdutórios, duas características peculiares. Adicionase a esses argumentos o fato de serem características de elevada herdabilidade e métodos de melhoramentos menos elaborados podem ser aplicados (VIANA et al. 2004; MORAES et al., 2005).

Ressalta-se, primeiramente, o fato de observar-se elevado poder de discriminação entre indivíduos associado à planta doadora de pólen ("genitor masculino"), a qual influencia com grande efetividade as características mensuráveis e discriminadoras de qualidade aos frutos obtidos. Tal peculiaridade gera indicativa inicial da necessidade da verificação da origem do pólen ao momento do cruzamento, o qual pode efetivamente contribuir para a obtenção de produto e sementes de melhor qualidade, conforme tem sido observado em experimentos de campo, onde se avaliam as progênies formadas a partir desses cruzamentos. Nesses experimentos, tem-se verificado, através de análises preliminares, o alto efeito de genitor masculino no rendimento de várias características avaliadas, confirmando os indicadores levantados neste trabalho.
E como decorrência do primeiro aspecto levantado, a utilização indiscriminada de plantas doadoras de pólen em esquemas de seleção massal pode inferir ganhos genéticos inconsistentes como atribuição da consideração não condizente do efeito "genitor masculino" durante os processos de cruzamento e seleção.

Em termos práticos, boas "genitoras femininas” poderão ser avaliadas sem maior destaque em função de seus frutos serem produtos de cruzamento com uma planta doadora de pólen inferior aos seus pares, como aquelas especificadas em G3, levando a formação de frutos com baixo rendimento para as características aqui estudadas. De outra forma, “genitoras femininas” geneticamente inferiores poderão, enganosamente, assumir lugar de destaque ao final de um processo da avaliação por terem sido submetidas ao cruzamento com um indivíduo de características produtivas excepcionais perante seus pares, tomando-se como exemplo o indivíduo 19, destacado dos demais na tabela 3 e na figura 1 .

Dessa forma, a seleção massal, que poderia ser recomendada como estratégia de melhoramento 


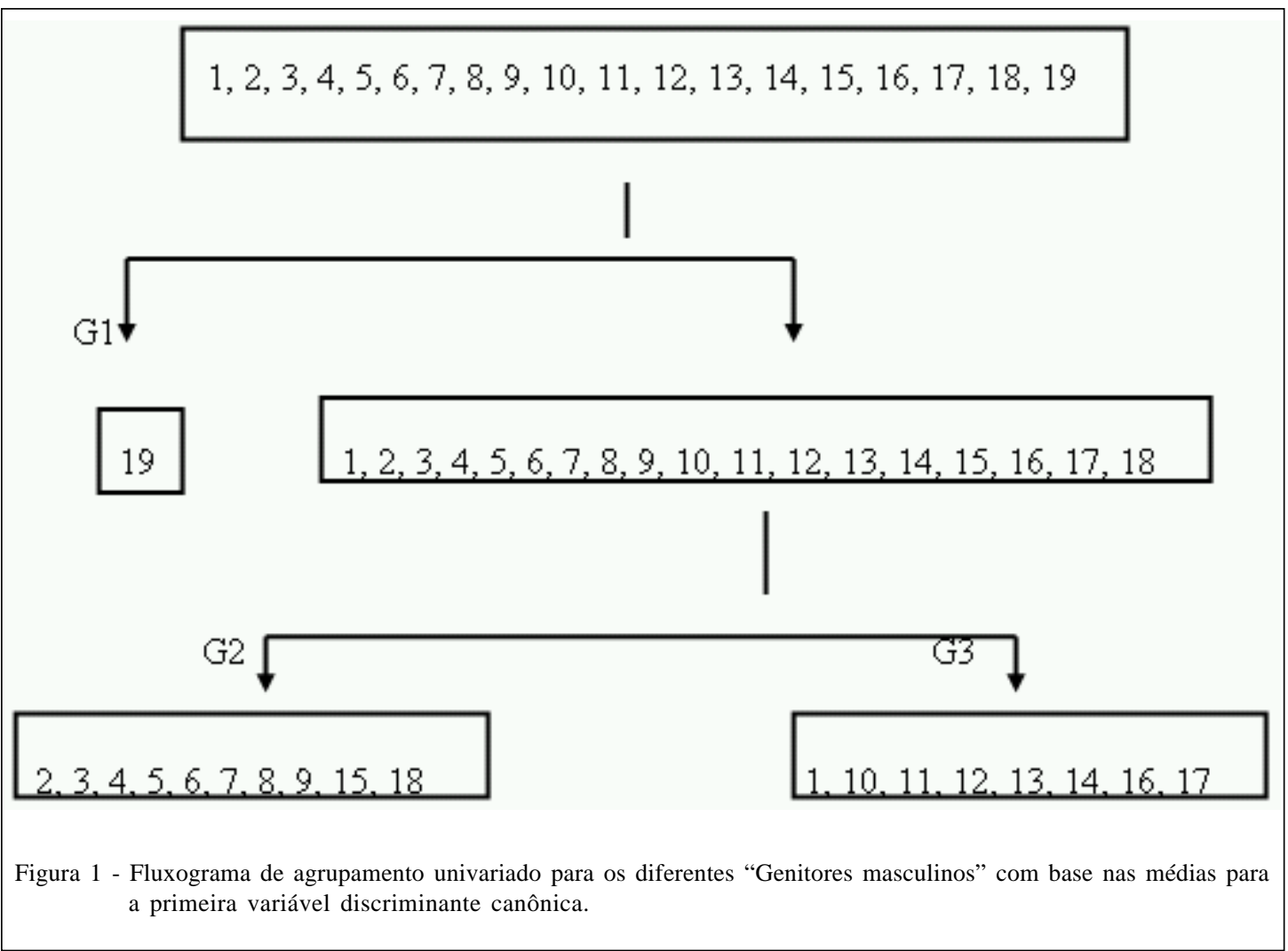

para essa cultura, devido a ter sido pouco explorada geneticamente na prática, gerará ganhos inexpressivos, uma vez que utiliza progenitores não selecionados na população. Sugere-se, portanto, que tal processo seja revisto, priorizando-se, simultaneamente, a seleção de plantas doadoras de pólen ("genitor masculinos”), bem como as plantas receptoras de pólen ("genitoras femininas”) para que, dessa forma, obtenham-se ganhos mais consistentes. Há que se destacar, finalmente, que a auto-incompatibilidade, característica dessa cultura, proporcionará uma suficiente diversidade de alelos para se evitar o estrangulamento da população através de cruzamentos entre indivíduos aparentados.

\section{CONCLUSÕES}

Estratégias de melhoramento para a cultura do maracujazeiro amarelo devem priorizar a escolha de ambos os genitores, com atenção maior a teste de progênies e possivelmente de irmãos completos, o que acarretará ganhos genéticos superiores em relação à seleção massal e suas derivações.

\section{REFERÊNCIAS}

CRUZ, C.D. Aplicação de algumas técnicas multivariadas no melhoramento de plantas. 1990. 95f. Tese (Doutorado em Genética e Melhoramento) - Escola Superior de Agricultura Luiz de Queiroz , USP, Piracicaba.

HARRIS, R.J. A primer of multivariate statistics. New York: Academic, 1975. 332p.

MELETTI, L.M.M. et al. Variabilidade genética em caracteres morfológicos, agronômicos e citogenéticos de populações de maracujazeiro-doce. Revista Brasileira de Fruticultura, v.25, p.275-278, 2003.

MORAES, M.C. et al. Genetic and phenotypic parameter estimates for yield and fruit quality traits from a single wide cross in yellow passion fruit. HortScience, v.40, n.7, p.19781981, 2005.

RAO, A.V. et al. Genetic divergence among some brown planthopper resistant rice varieties. Indian Journal of Genetic Plant Breeding, v.41, p.179-185, 1981.

SCOTT, A.J.; KNOTT, M. A cluster analysis method for grouping means in the analysis of variance. Biometrics, v.30, p.507-512, 1974.

SEARLE, S.R. Matrix algebra for the biological sciences. New York: Jonh Willey \& Sons, 1966. 513p.

Ciência Rural, v.37, n.6, nov-dez, 2007. 
SOUZA, M.M. et al. Meiotic irregularities and pollen viability in Passiflora edmundoi Sacco (Passifloraceae). Caryologia v.56, p.453-51, 2003.

SOUZA, M.M. et al. Flower receptivity and fruit characteristics associate to time of pollination in yellow passion fruit Passiflora edulis sims f. falvicarpa. Scientia Horticulture v.1, p.1-13, 2004a.

SOUZA, M.M. et al. Flow cytometric analysis of genome size variation in some Passiflora species. Hereditas v.1, p.1-8, 2004b.

STEEL, R.G.D. et al. Principles and procedures of statistics. A biometrical approach. 3.ed. New York: McGraw Hill, 1997. 633p.
VIANA, A.P. et al. Simple and canonic correlation between agronomical and fruit quality traits in yellow passion fruit (Passiflora edulis f. flavicarp) populations. Crop Breeding and Applied Biotechnology v.3, p.133-140, 2003a.

VIANA, A.P. et al. Diversidade genética entre genótipos comerciais de maracujazeiro amarelo (Passiflora edulis $\mathrm{f}$. flavicarpa) e entre espécies nativas de Passiflora determinada por marcadores RAPD. Revista Brasileira de Fruticultura, v.25, n.3, p.489-493, 2003b.

VIANA, A.P. et al. Parâmetros genéticos em populações de maracujazeiro amarelo. Revista Ceres v.51, p.541-551, 2004.

VIANA, AP. et al. Genetic diversity in yellow passion fruti populations. Crop Breeding and Applied Biotechnology, v.6, p.87-94, 2006. 